\title{
Coherent phonon control
}

O. Synnergren, T. N. Hansen, S. Canton, H. Enquist, P. Sondhauss, A. Srivastava, and J. Larsson

Citation: Appl. Phys. Lett. 90, 171929 (2007); doi: 10.1063/1.2734369

View online: http://dx.doi.org/10.1063/1.2734369

View Table of Contents: http://aip.scitation.org/toc/apl/90/17

Published by the American Institute of Physics

\section{AIP $\mid$ Applied Physics Letters}

Save your money for your research.

It's now FREE to publish with us -

no page, color or publication charges apply. 


\title{
Coherent phonon control
}

\author{
O. Synnergren, ${ }^{\text {a) }}$ T. N. Hansen, S. Canton, H. Enquist, P. Sondhauss, \\ A. Srivastava, and J. Larsson ${ }^{\text {b) }}$ \\ Lund University, P.O. Box 118, SE-221 00 Lund, Sweden
}

(Received 8 December 2006; accepted 2 April 2007; published online 27 April 2007)

\begin{abstract}
Trains of ultrashort laser pulses have been used to generate and to coherently control acoustic phonons in bulk InSb. The coherent acoustic phonons have been probed via time-resolved $\mathrm{x}$-ray diffraction. The authors show that phonons of a particular frequency can either be enhanced or canceled. They have carried out simulations to understand the size of the effects and the levels of cancellation. () 2007 American Institute of Physics. [DOI: 10.1063/1.2734369]
\end{abstract}

Lasers producing femtosecond pulses offer the unique possibility to control the structural dynamics of matter on the atomic scale. They can be used to, e.g., excite coherent acoustic and optical phonons, trigger phase transitions, or initiate chemical reactions. X-rays are the ideal means to probe the laser initiated atomic motion, since they provide atomic resolution and are independent of the chemical environment as they mainly interact with the core electrons.

Time-resolved $\mathrm{x}$-ray diffraction (TXRD) has been applied to probe the generation of coherent acoustic phonons by femtosecond lasers ${ }^{1-6}$ and how free carriers influence this process, e.g., energy transfer via carrier diffusion. ${ }^{7,8}$ Coherent optical phonons and folded phonons in periodic heterostructures have also been observed via TXRD. ${ }^{9-11}$ Nonthermal melting of semiconductors has been studied in detail. ${ }^{12-15}$ The kinetics of other more subtle photoinduced phase transitions ${ }^{16-19}$ have also been studied by TXRD. ${ }^{20-22}$ Coherent-control experiments in solid-state systems using optical probes have been performed ${ }^{23-25}$ on the path towards coherently controlling the structural phase of matter. For most structural phase transitions, phonons drive the structural change. In order to be able to control these transitions it is crucial to get a handle on the creation and annihilation of phonons from selected modes. Lindenberg et al. ${ }^{26}$ showed that the modulation of diffracted x-rays can be enhanced or canceled by using two consecutive laser pulses instead of one. A topic of discussion has been as to what extent the enhanced x-ray modulation is due to increased laser fluence (the two laser pulses had each the same energy as the single pulse) rather than the control of atomic motion.

In the present experiment, we show that the change in $\mathrm{x}$-ray reflectivity indeed is due to a selective change in the amplitude of particular phonon modes. This is achieved by increasing the temporal window so that Fourier methods can be applied, which enables us to show and discuss how interference takes place. We use a pulse train with variable delays to modify the phonon spectrum. This yields a considerably stronger enhancement of a selected mode compared to Lindenberg et al. We have used pulse trains with different lengths which illustrates the importance of dephasing and $\mathrm{x}$-ray absorption in the visualization of acoustic phonons using TXRD. This shows how far the concept of enhancing individual modes with multiple pulses can be taken. We have also performed computer simulations to understand the effect

\footnotetext{
a) Also at Malmö University, 20506 Malmö, Sweden.

${ }^{b)}$ Electronic mail: jorgen.larsson@fysik.lth.se
}

of the wave propagation into the crystal. We discuss the data in the spatial, temporal, and spectral domains.

The setup at beamline D611, MAX-Lab is described in detail elsewhere. ${ }^{27}$ Monochromatized radiation with a bandwidth of $\Delta E / E=2 \times 10^{-4}$ was used in the experiment. The $\mathrm{X}$-ray spot size was $250 \times 150 \mu \mathrm{m}^{2}$ and the divergence was $7 \times 0.7 \mathrm{mrad}^{2}$ (horizontal $\times$ vertical). Laser pulses synchronized to the MAX II electron storage ring with a duration of $40 \mathrm{fs}$ and a center wavelength of $780 \mathrm{~nm}(1.5 \mathrm{eV})$ were used for exciting the sample. The laser was operated at a repetition rate of $4.25 \mathrm{kHz}$. The energy per pulse in the pump beam was $5 \mu \mathrm{J}$ and the spot size was $0.9 \times 0.5 \mathrm{~mm}^{2}$, resulting in a fluence of $1.4 \mathrm{~mJ} / \mathrm{cm}^{2}$ (well below the damage threshold). A pulse train of up to 16 pulses separated by 25-100 ps was created by four consecutive Michelson interferometerlike delay stages using polarization optics to maximize throughput. A streak camera equipped with a CsI transmission photocathode was used to record the time-resolved $\mathrm{x}$-ray intensity. ${ }^{28} \mathrm{~A}$ temporal window large enough to cover the $400 \mathrm{ps}$ x-ray pulse was chosen, yielding a resolution of 15 ps. The sample was a $600-\mu$ m-thick InSb crystal (direct band gap of $0.18 \mathrm{eV}$ ). It was cut at $8^{\circ}$ to the (111) plane and probed by $3630 \mathrm{eV}$ x-ray radiation, yielding the incidence and exit angles to be $17^{\circ}$ and $33^{\circ}$, respectively.

We can think of the launched strain wave as being built up by a range of acoustic phonon modes. The modes extend throughout the crystal but due to the very large range of frequencies involved they only interfere constructively in a limited depth range. When we probe these phonons with $\mathrm{x}$-ray diffraction, we can in principle select a particular phonon frequency to visualize. ${ }^{2}$ A single excited phonon mode modifies the Laue condition to $\boldsymbol{k}_{H}-\boldsymbol{k}_{I}=\boldsymbol{G} \pm \boldsymbol{Q}$, where $\boldsymbol{k}_{I}$ and $\boldsymbol{k}_{H}$ are the wave vectors of incident and reflected x rays, $\boldsymbol{G}$ the reciprocal lattice vector for the reflection used, and $\boldsymbol{Q}$ the wave vector of the probed phonon. This will give rise to sidebands of the rocking curve that oscillate in time with the frequency of the phonon mode. In other words, we can modify the modulus of $\boldsymbol{k}_{I}$ and $\boldsymbol{k}_{H}$ by changing the x-ray energy, thereby probing a given $\boldsymbol{Q}$ and $\omega$. This has been illustrated for symmetric and asymmetric cut samples by Larsson et al. ${ }^{5}$ In order to probe a phonon mode with an oscillation period of $50 \mathrm{ps}$, the x-ray energy used in the experiment was $\pm 9 \mathrm{eV}$ off the rocking curve peak.

Results from four different excitation schemes are shown in Fig. 1: a single pulse, four equidistant pulses separated by $50 \mathrm{ps}(0,50,100$, and $150 \mathrm{ps})$, four nonequidistant pulses $(0$, 25,100 , and $125 \mathrm{ps}$ ), and four equidistant pulses separated 


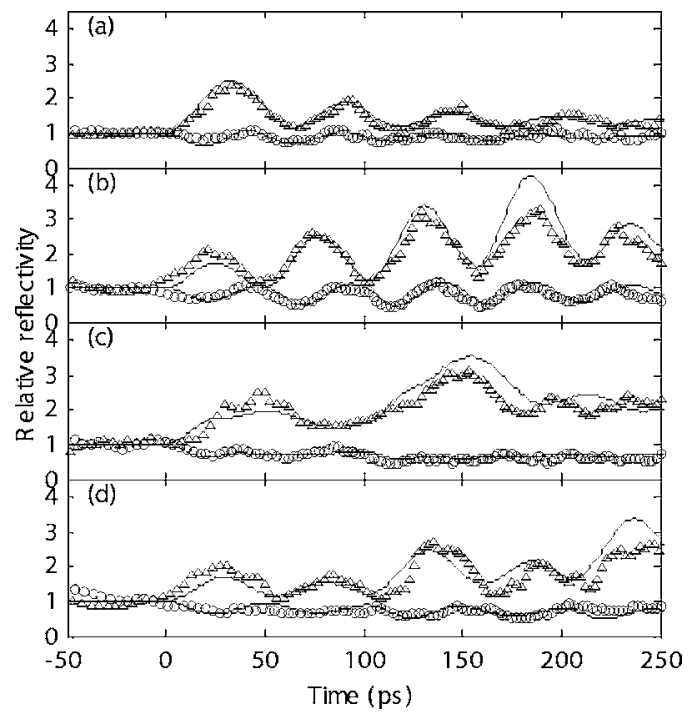

FIG. 1. Measured (triangles on expansion side, circles on compression side) and simulated (lines) modulated x-ray reflectivity: (a) pump with a single laser pulse, (b) four equidistant pulses 50 ps apart, (c) four nonequidistant pulses at $0,25,100$, and 125 ps respectively, and (d) four equidistant pulses 100 ps apart.

by 100 ps $(0,100,200$, and 300 ps $)$. In the case of the equidistant pulses separated by 50 ps the oscillation amplitude of the reflectivity increases from pulse to pulse in contrast to the single pulse data. In the case of the nonequidistant pulses the oscillations are efficiently canceled after a half period. When the exciting laser pulses are separated by twice the period time, an enhancement is seen on every second phonon period in the data. The enhancement in this case is less pronounced compared to when the pulses have a one period separation. This is because we probe a range of phonon modes, not just a single one, and observe dephasing. Absorption of the x-rays also matters when coherent phonons are probed in this way.

In an experiment, a range of phonon modes are visualized due to the finite bandwidth of the monochromator. They interfere constructively only in a limited spatial range where the modes are in phase. This effect, known as dephasing, limits the effective probe depth of the visualization. In our case the bandwidth of $\Delta E / E=2 \times 10^{-4}$ corresponds to a $0.7 \mathrm{eV}$ width which is $8 \%$ of the offset of the x-ray energy from the Bragg condition. This means that there is an $8 \%$ full width at half maximum (FWHM) uncertainty in the probed phonon frequency. This frequency uncertainty corresponds to $1.6 \mathrm{GHz}$ for the observed $20 \mathrm{GHz}$ oscillation. Assuming a Gaussian shape, the dephasing time is 270 ps FWHM. Taking the sound speed in the direction perpendicular to the surface of $3860 \mathrm{~m} / \mathrm{s}$ into account we obtain a dephasing depth of $1.1 \mu \mathrm{m}$.

Another factor reducing the probe depth is the x-ray absorption. In our experiments the linear absorption length of the $\mathrm{x}$-ray probe is $4.5 \mu \mathrm{m}$ at $3630 \mathrm{eV}$, giving a probe depth around $0.9 \mu \mathrm{m}$ in this geometry. This is smaller but similar to the distance over which dephasing occurs.

When we design pulse sequences in order to control the visualized phonon modes, we are limited by probe depth. The four-pulse train generated a strain wave extending over approximately $600 \mathrm{~nm}$ in depth, the exact value depending on whether an enhancement or cancellation scheme was used. When we increase the pulse spacing to match every

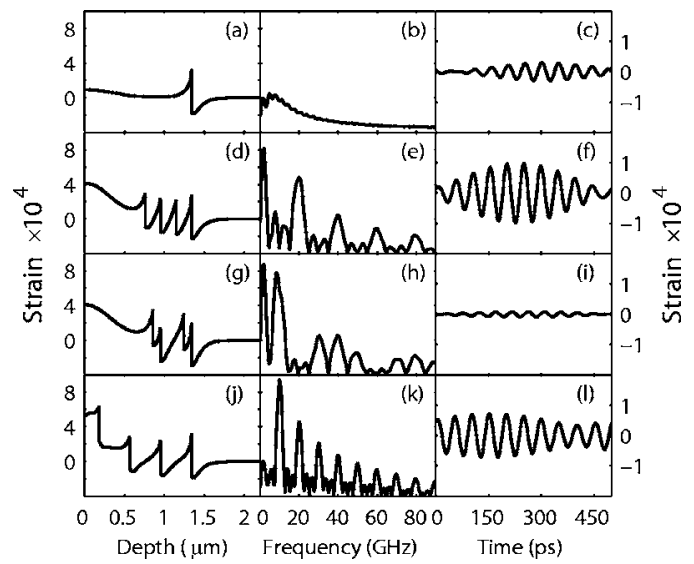

FIG. 2. [(a), (d), (g), and (j)] Calculated strain profiles after 250 ps, [(b), (e), (h), and (k)] Fourier transforms of the strain profiles $300 \mathrm{~nm}$ into the sample, and [(c), (f), (i), and (1)] strain profiles after band pass filtering with the observed spectral window. Results are shown for (a)-(c) pump with a single laser pulse, $[(\mathrm{d})-(\mathrm{f})]$ four equidistant pulses $50 \mathrm{ps}$ apart, $[(\mathrm{g})-(\mathrm{i})]$ four nonequidistant pulses at $0,25,100$, and $125 \mathrm{ps}$, and [(j)-(1)] four equidistant pulses 100 ps apart.

other phonon period, the strain wave extends over a depth larger than the probe depth, and therefore, the enhancement is less pronounced which is in agreement with our result displayed in Fig. 1. We also tried extending the train from four to eight pulses. This also meant that the depth of the strain profile was increased beyond the probe depth and did not give a substantial enhancement of the $\mathrm{x}$-ray signal.

Time-resolved $\mathrm{x}$-ray diffraction simulations have been made by numerically solving the Takagi-Taupin equation for strained crystals. $^{29,30}$ The laser generated strain consists of two parts, a nonpropagating surface component and a propagating acoustic wave, the latter being equivalent to a set of coherent phonons. The surface strain is mainly due to thermal expansion and relaxes by heat conduction. It has been modeled using the heat conduction equation. The acoustic wave is a response to the rapid surface expansion and has been described by Thomsen et al. ${ }^{31}$ In order to illustrate the phonon spectrum for different excitation schemes, the Fourier transform of the calculated strain profile is shown in Fig. 2. The left column in Fig. 2 shows the strain profile after $250 \mathrm{ps}$ for four schemes, and the center column shows the corresponding temporal Fourier transforms. Compared to the strain occurring from a single laser pulse, the strain component at $20 \mathrm{GHz}$ is larger in the cases of equidistant laser pulses, both for 50 and $100 \mathrm{ps}$ separations. In the case of 100 ps separation there is also a large strain component at $10 \mathrm{GHz}$. In the case of the nonequidistant laser pulses (25, 50,100 , and $125 \mathrm{ps}$ ), there are many strain components, but the component at $20 \mathrm{GHz}$ is very small. The influence of dephasing in our experiment is illustrated in the right column of Fig. 2, where we see the strain from the visualized phonon modes only. This was created by filtering the left column with a frequency filter corresponding to the monochromator bandwidth.

We have also analyzed the frequency content in our measured data. Figure 3 shows the temporal Fourier transforms of the experimentally measured relative $\mathrm{x}$-ray reflectivities shown in Fig. 1. In the case of a single excitation pulse (solid line), there is a peak at $20 \mathrm{GHz}$, corresponding to a period time of $50 \mathrm{ps}$, just as expected. For the case with four equidistant pulses separated by 50 ps (dotted line), this peak is 


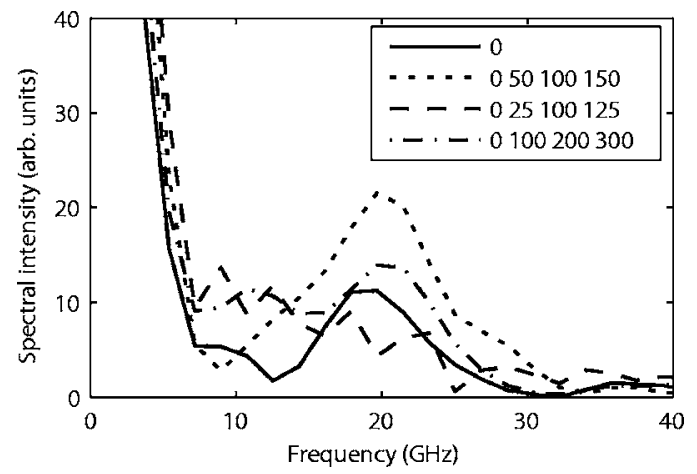

FIG. 3. Fourier transform of the relative reflectivity shown in Fig. 1. Data on the expansion side (triangles) have been used for the Fourier transform. The widths of the peaks are a result of the Gaussian window function that was used.

doubled in amplitude, showing an increase of the probed range of phonons. In the case of four equidistant pulses separated by $100 \mathrm{ps}$ (dash-dotted line), the peak at $20 \mathrm{GHz}$ is also increased somewhat, but there is also a peak at $10 \mathrm{GHz}$, corresponding to $100 \mathrm{ps}$. In the case with nonequidistant pulses (dashed line), the phonon mode at $20 \mathrm{GHz}$ has been canceled out and there is no clear peak at this frequency.

In conclusion, we have shown that individual phonon modes can be driven to large amplitudes or canceled using a train of laser pulses. This effect comes from interfering waves. The two factors limiting the enhancement of phonons of a given frequency are photoabsorption of the $\mathrm{x}$ rays and dephasing of the finite range of phonon modes which are visualized.

The authors would like to thank the Swedish Research Council (VR), the Swedish Foundation for Strategic Research (SSF), the Crafoord Foundation, Carl Tryggers Stiftelse, and the FLASH MC-RTN.

${ }^{1}$ C. Rose-Petruck, R. Jimenez, T. Guo, A. Cavalleri, C. W. Siders, F. Raksi, J. A. Squier, B. C. Walker, K. R. Wilson, and C. P. J. Barty, Nature (London) 398, 310 (1999).

${ }^{2}$ A. M. Lindenberg, I. Kang, S. L. Johnson, T. Missalla, P. A. Heimann, Z. Chang, J. Larsson, P. H. Bucksbaum, H. C. Kapteyn, H. A. Padmore, R. W. Lee, J. S. Wark, and R. W. Falcone, Phys. Rev. Lett. 84, 111 (2000). ${ }^{3}$ D. A. Reis, M. F. DeCamp, P. H. Bucksbaum, R. Clarke, E. Dufresne, M. Hertlein, R. Falcone, H. Kapteyn, M. Murnane, J. Larsson, Th. Missalla, and J. Wark, Phys. Rev. Lett. 86, 3072 (2001).

${ }^{4}$ M. F. DeCamp, D. A. Reis, P. H. Bucksbaum, B. Adams, J. M. Caraher, R. Clarke, C. W. S. Conove, E. M. Dufresne, R. Merlin, V. Stoica, and J. K. Wahlstrand, Nature (London) 413, 825 (2001).

${ }^{5}$ J. Larsson, A. Allen, P. H. Bucksbaum, R. W. Falcone, A. Lindenberg, G. Naylor, T. Missalla, D. A. Reis, K. Scheidt, A. Sjögren, P. Sondhauss, M. Wulff, and J. S. Wark, Appl. Phys. A: Mater. Sci. Process. 75, 467 (2002). ${ }^{6}$ A. H. Chin, R. W. Schoenlein, T. E. Glover, P. Balling, W. P. Leemans, and C. V. Shank, Phys. Rev. Lett. 83, 336 (1999).

${ }^{7}$ M. F. DeCamp, D. A. Reis, A. Cavalieri, P. H. Bucksbaum, R. Clarke, R.
Merlin, E. M. Dufresne, D. A. Arms, A. M. Lindenberg, A. G. MacPhee, Z. Chang, B. Lings, J. S. Wark, and S. Fahy, Phys. Rev. Lett. 91, 165502 (2003).

${ }^{8}$ A. Cavalleri, C. W. Siders, C. Rose-Petruck, R. Jimenez, Cs. Tóth, J. A. Squier, C. P. J. Barty, and K. R. Wilson, Phys. Rev. B 63, 193306 (2001). ${ }^{9}$ K. Sokolowski-Tinten, C. Blome, J. Bloms, A. Cavalleri, C. Dietrich, A. Tarasevitch, I. Uschmann, E. Förster, M. Kammler, M. Horn-von-Hoegen, and D. von der Linde, Nature (London) 422, 287 (2003).

${ }^{10}$ M. Bargheer, N. Zhavoronkov, Y. Gritsai, J. C. Woo, D. S. Kim, M. Woerner, and T. Elsaesser, Science 306, 1771 (2004).

${ }^{11}$ P. Sondhauss, J. Larsson, M. Harbst, G. A. Naylor, A. Plech, K. Scheidt, O. Synnergren, M. Wulff, and J. S. Wark, Phys. Rev. Lett. 94, 125509 (2005).

${ }^{12}$ C. V. Shank, R. Yen, and C. Hirlimann, Phys. Rev. Lett. 51, 900 (1983).

${ }^{13}$ A. Rousse, C. Rischel, S. Fourmaux, I. Uschmann, S. Sebban, G. Grillon, $\mathrm{Ph}$. Balcou, E. Förster, J. P. Geindre, P. Audebert, J. C. Gauthier, and D. Hulin, Nature (London) 410, 65 (2001).

${ }^{14}$ K. Sokolowski-Tinten, C. Blome, C. Dietrich, A. Tarasevitch, M. H. von Hoegen, D. von der Linde, A. Cavalleri, J. Squier, and M. Kammler, Phys. Rev. Lett. 87, 225701 (2001).

${ }^{15}$ A. M. Lindenberg, J. Larsson, K. Sokolowski-Tinten, K. J. Gaffney, C. Blome, O. Synnergren, J. Sheppard, C. Caleman, A. G. MacPhee, D. Weinstein, D. P. Lowney, T. K. Allison, T. Matthews, R. W. Falcone, A. L. Cavalieri, D. M. Fritz, S. H. Lee, P. H. Bucksbaum, D. A. Reis, J. Rudati, P. H. Fuoss, C. C. Kao, D. P. Siddons, R. Pahl, J. Als-Nielsen, S. Duesterer, R. Ischebeck, H. Schlarb, H. Schulte-Schrepping, T. Tschentscher, J. Schneider, D. von der Linde, O. Hignette, F. Sette, H. N. Chapman, R. W. Lee, T. N. Hansen, S. Techert, J. S. Wark, M. Bergh, G. Huldt, D. van der Spoel, N. Timneanu, J. Hajdu, R. A. Akre, E. Bong, P. Krejcik, J. Arthur, S. Brennan, K. Luening, and J. B. Hastings, Science 308, 392 (2005).

${ }^{16}$ K. Nasu, H. Ping, and H. Mizouchi, J. Phys.: Condens. Matter 13, R693 (2001).

${ }^{17}$ M. Buron and E. Collet, J. Phys.: Conf. Ser. 21, 1 (2005).

${ }^{18}$ J. Siegel, A. Schropp, J. Solis, C. N. Afonso, and M. Wuttig, Appl. Phys. Lett. 84, 2250 (2004).

${ }^{19}$ S. Fahy and R. Merlin, Phys. Rev. Lett. 73, 1122 (1994).

${ }^{20}$ E. Collet, M.-H. Lemée-Cailleau, M. Buron-Le Cointe, H. Cailleau, M. Wulff, T. Luty, S.-Y. Koshihara, M. Meyer, L. Toupet, P. Rabiller, and S. Techert, Science 300, 612 (2003).

${ }^{21}$ A. Cavalleri, Cs. Tóth, C. W. Siders, J. A. Squier, F. Ráksi, P. Forget, and J. C. Kieffer, Phys. Rev. Lett. 87, 237401 (2001).

${ }^{22}$ J. Larsson, P. Sondhauss, O. Synnergren, M. Harbst, P. A. Heimann, A. M. Lindenberg, and J. S. Wark, Chem. Phys. 299, 157 (2004).

${ }^{23}$ É. D. Murray, D. M. Fritz, J. K. Wahlstrand, S. Fahy, and D. A. Reis, Phys. Rev. B 72, 060301 (2005).

${ }^{24}$ Ü. Özgür, C.-W. Lee, and H. O. Everitt, Phys. Rev. Lett. 86, 5604 (2001).

${ }^{25}$ N. H. Bonadeo, J. Erland, D. Gammon, D. Park, D. S. Katzer, and D. G. Steel, Science 282, 1473 (1998).

${ }^{26}$ A. M. Lindenberg, I. Kang, S. L. Johnson, R. W. Falcone, P. A. Heimann, Z. Chang, R. W. Lee, and J. S. Wark, Opt. Lett. 27, 869 (2002).

${ }^{27}$ M. Harbst, T. N. Hansen, C. Caleman, W. K. Fullagar, P. Jönsson, P. Sondhauss, O. Synnergren, and J. Larsson, Appl. Phys. A: Mater. Sci. Process. 81, 893 (2005).

${ }^{28}$ J. Larsson, Z. Chang, E. Judd, P. J. Schuck, R. W. Falcone, P. A. Heimann, H. A. Padmore, H. C. Kapteyn, P. H. Bucksbaum, M. M. Murnane, R. W. Lee, A. Machacek, J. S. Wark, X. Liu, and B. Shan, Opt. Lett. 22, 1012 (1997).

${ }^{29}$ S. Takagi, Acta Crystallogr. 15, 1311 (1962).

${ }^{30}$ P. Sondhauss and J. S. Wark, Acta Crystallogr., Sect. A: Found. Crystallogr. 59, 7 (2003).

${ }^{31}$ C. Thomsen, H. T. Grahn, H. J. Maris, and J. Tauc, Phys. Rev. B 34, 4129 (1986). 